\title{
Subcellular localization of the porcine deltacoronavirus nucleocapsid protein
}

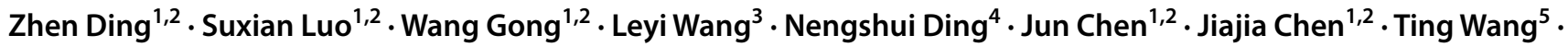

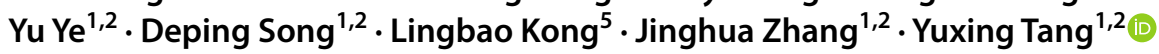

Received: 15 January 2020 / Accepted: 17 August 2020 / Published online: 17 September 2020

(c) Springer Science+Business Media, LLC, part of Springer Nature 2020

\begin{abstract}
Porcine deltacoronavirus (PDCoV) has been recently identified as an emerging enteropathogenic coronavirus that mainly infects newborn piglets and causes enteritis, diarrhea and high mortality. Although coronavirus $\mathrm{N}$ proteins have multifarious activities, the subcellular localization of the PDCoV N protein is still unknown. Here, we produced mouse monoclonal antibodies against the PDCoV N protein. Experiments using anti-haemagglutinin antibodies and these monoclonal antibodies revealed that the PDCoV N protein is shuttled into the nucleolus in both ectopic PDCoV N-expressing cells and PDCoVinfected cells. The results of deletion mutagenesis experiments demonstrated that the predicted nucleolar localization signal at amino acids 295-318 is critical for nucleolar localization. Cumulatively, our study yielded a monoclonal antibody against the PDCoV N protein and revealed a mechanism by which the PDCoV N protein translocated into the nucleolus. The tolls and findings from this work will facilitate further investigations on the functions of the PDCoV N protein.
\end{abstract}

Keywords Porcine deltacoronavirus $\cdot$ Nucleocapsid protein $\cdot \mathrm{mAb} \cdot$ Nucleolar localization

\section{Introduction}

Porcine deltacoronavirus (PDCoV), an emerging swine enteric pathogen, is a major causative agent of watery diarrhea, vomiting, and mortality in piglets, leading to significant losses in the pig industry $[1,2]$. In addition to causing global outbreaks of diarrhea in pigs, PDCoV can cross the species barrier to infect calves, chickens, and even humans [3-5], thus posing a significant threat to public health. PDCoV is an enveloped RNA virus with a single-stranded, positive-sense genome. It is classified into the genus Deltacoronavirus, in the family of Coronaviridae and the order Nidovirale. PDCoV has the shortest genome (approximately $25.4 \mathrm{~kb}$ in length) among the known members in the family of Coronaviridae. Two-thirds of the genome at the 5' ORF1a/1b encodes pp1a and pp1ab, which are two polymerase proteins that can be proteolytically cleaved into 15 mature non-structural proteins (nsps), while the remaining one-third of the genome at $3^{\prime}$ terminal region encodes four structural proteins and three newly identified accessory proteins, NS6, NS7, and NS7a. The four structural proteins are the spike (S), envelope (E), membrane (M) and nucleocapsid (N) proteins [6-9].

5 Institute of Pathogenic Microorganism and College of Bioscience and Engineering, Jiangxi Agricultural University, Nanchang, Jiangxi, China 
Among these proteins, $\mathrm{N}$ protein is structurally and functionally conserved within all the coronaviruses ( $\mathrm{CoVs})$, and it plays critical roles in packaging the viral genomic RNA into the virion for viral assembly $[10,11]$. Additionally, the $\mathrm{N}$ protein is the most abundant and ubiquitous viral protein in the context of $\mathrm{CoV}$ infection or assembled virions, and has roles in multifarious activities throughout the life cycle of a CoV [12]. In addition to promoting viral genome transcription or replication, the $\mathrm{N}$ protein also modulates the processes of inflammatory cytokine productions, RNA interference and apoptosis, and counteracting the host innate immune defense [13-16]. Interestingly, based on studies of representative $\mathrm{CoVs}$, a cytoplasmic nucleolar location pattern is common for the $\mathrm{N}$ proteins of several $\mathrm{CoVs}$, including porcine epidemic diarrhea virus (PEDV), mouse hepatitis virus (MHV) and infectious bronchitis virus (IBV) [17-19]. Proteins imported to the nucleolus contain at least one nucleolar localization signal (NoLS) that specifies their nucleolar localization; however, how viral or cellular proteins traffic into the nucleolus is not clearly understood [17]. Meanwhile, the localization of the PDCoV N protein and its traffic mechanisms are yet unknown.

In this study, we produced monoclonal antibodies (mAbs) against the PDCoV N protein, and then used them to observe that the PDCoV N protein distribution pattern in the cytoplasm and nucleolus in both ectopic PDCoV N-expression cells and PDCoV-infected cells. We also performed deletion mutagenesis to identify potential NoLS. The findings from these experiments will provide new insights into the properties and functions of the PDCoV N protein.

\section{Materials and methods}

\section{Ethics statement}

With the approval of the Laboratory Animal Ethics Committee of Jiangxi Agricultural University and in accordance with The Guidelines for the Care of Laboratory Animals established by the Ministry of Agriculture of China, an animal use protocol (JXAULL-20190016) was used. The mice used to produce ascites for harvesting monoclonal antibodies against the $\mathrm{N}$ protein of PDCoV were euthanized. Ascites were harvested immediately on the day when abdominal enlargement was observed to avoid ascites accumulation, which may cause distress.

\section{Cell, virus and reagents}

LLC-PK1 cells, a porcine kidney cell line, were purchased from ATCC and subsequently cultured in Dulbecco's modified Eagle's medium (Gibco) containing 10\% heat-inactivated fetal bovine serum (PAN-biotech) and a combination of penicillin and streptomycin (Solarbio), in a humidified incubator with an atmosphere of $5 \% \mathrm{CO}_{2}$ at $37^{\circ} \mathrm{C}$. PDCoV strain CH/JXJGS01/2016 (GenBank accession number KY293677.1) was isolated in our laboratory in 2016 from a newborn piglet with diarrhea. Mouse $\mathrm{mAb}$ against $\beta$-actin and hemagglutinin (HA) were bought from Medical and Biological Laboratories (Japan). Rabbit anti-B23 antibody was purchased from Proteintech (CHI, USA). Horseradish peroxidase (HRP)-conjugated goat anti-mouse $\mathrm{IgG}(\mathrm{H}+\mathrm{L})$ was bought from antGene (China). FITC-conjugated goat anti-mouse $\operatorname{IgG}(\mathrm{H}+\mathrm{L})$ and Alexa Fluor ${ }^{\circledR} 594$ donkey antirabbit $\operatorname{IgG}(\mathrm{H}+\mathrm{L})$ were bought from and TransGen Biotech (China). All enzymes used for the cloning procedures were purchased from Takara (Dalian, China). Freund's complete/ incomplete adjuvants, polyethylene glycol 1450 and HT/ HAT medium were purchased from Sigma-Aldrich (MO, USA).

\section{Plasmids}

To construct the DNA expression vector pCAGGS-HAPDCoV-N coding an HA-tagged PDCoV N protein, standard reverse transcription (RT)-PCR with primers N1-F and N3-R primers was used to amplify the PDCoV N gene. The RNA from LLC-PK1 cells infected with PDCoV strain CH/ JXJGS01/2016 was extracted and used as a template for reverse transcription, generating cDNA for amplification. Mutants of the PDCoV N protein $\mathrm{N}^{\mathrm{R} 157 \mathrm{~A}}, \mathrm{~N}^{\Delta 161-197}, \mathrm{~N}^{\Delta}$ ${ }^{295-318}, \mathrm{~N}^{\mathrm{R} 157 \mathrm{~A} \Delta}$ 161-197$, \mathrm{N}^{\mathrm{R} 157 \mathrm{~A} \Delta} \mathbf{2 0 5 5 - 3 1 8}, \mathrm{N}^{\Delta 161-197 \Delta 295-318}$
Table 1 Primers and templets using in plasmid construction

\begin{tabular}{lll}
\hline Fragment amplified & Primers used & Templates used \\
\hline WT N (aa 1 to 342) & N1-F/N3-R & PDCoV \\
$\mathrm{N}^{\mathrm{R} 157 \mathrm{~A}}$ & N1-F/N157-R and N157-F/N3-R & WT N \\
$\mathrm{N}^{\Delta 161-197}$ & N1-F/N1-R and N2-F/N3-R & WT N \\
$\mathrm{N}^{\Delta 295-318}$ & N1-F/N2-R and N3-F/N3-R & WT N \\
$\mathrm{N}^{\mathrm{R} 157 \mathrm{~A} \Delta 161-197}$ & N1-F/N157-R and N2-F/N3-R & $\mathrm{N}^{\mathrm{R} 157 \mathrm{~A}}$ \\
$\mathrm{~N}^{\mathrm{R} 157 \mathrm{~A} \Delta 295-318}$ & N1-F/N2-R and N3-F/N3-R & $\mathrm{N}^{\mathrm{R} 157 \mathrm{~A}}$ \\
$\mathrm{~N}^{\Delta 161-197 \Delta 295-318}$ & N1-F/N2-R and N3-F/N3-R & $\mathrm{N}^{\Delta 161-197}$ \\
$\mathrm{~N}^{\mathrm{R} 157 \mathrm{~A} \Delta 161-197 \Delta 295-318}$ & $\mathrm{~N} 1-\mathrm{F} / \mathrm{N} 157-\mathrm{R}$ and N157-F/N3-R & $\mathrm{N}^{\Delta 161-197 \Delta 295-318}$ \\
\hline
\end{tabular}


Table 2 Primer sequences for amplification of PDCoV $\mathrm{N}$ gene and mutants

\begin{tabular}{ll}
\hline Name of primers & Sequence $\left(5^{\prime} \rightarrow 3^{\prime}\right)$ \\
\hline N1-F & TTTGAATTC ATGGCTGCACCAGTAGTCCCTA \\
N1-R & CTGAGAAATGGTTTTAGATTGAGATCTTGGGCC \\
N2-F & AGATCTCAATCTAAAACCATTTCTCAGGTATTTGGC \\
N2-R & TGCTGGCAGAGTTACTTTGGTGGGTGGCTC \\
N3-F & CCACCCACCAAAGTAACTCTGCCAGCAGACAAA \\
N3-R & TGGATCGATTACTACGCTGCTGATTCCTGCTTTA \\
N157-F & TCTGGAGTTAACAGATTGAGATGCTGGGCC \\
N157-R & AGTGGCCCAGCATCTCAATCTGTTAACTCC \\
\hline
\end{tabular}

The fonts-bold mean protective bases; the italics mean restriction enzyme cutting sites and $\mathrm{N}^{\mathrm{R} 157 \mathrm{~A} \Delta}$ 161-197 $\Delta$ 295-318 were constructed by truncation and/or site-directed mutagenesis (as described previously [20]) with overlap extending PCR employing the indicated templates and primers, listed in Tables 1 and 2. PCR products were digested with EcoR I and Cla I, followed by ligation into pCAGGS-HA. All constructs were verified by DNA sequencing. pCold-PDCoV-N that can express His-tagged $\mathrm{N}$ protein and recombinant PDCoV $\mathrm{N}$ protein that was expressed and purified from Escherichia coli were stored in our lab [21].

\section{Enzyme-linked immunosorbent assay (ELISA)}

To establish an ELISA for screening hybridomas secreting mAbs specific to the $\mathrm{N}$ protein of PDCoV, a standard method was employed. Briefly, the recombinant PDCoV $\mathrm{N}$ protein $(5 \mu \mathrm{g} / \mathrm{ml})$ was coated onto $96-$ well ELISA plates. The coated plates were washed three times with 0.01 M PBS ( $\mathrm{pH} 7.2)$ and then blocked with 5\% skimmed milk. After three times washing, the plates were incubated with the sera of mice who had been immunized with the recombinant PDCoV $\mathrm{N}$ protein. Subsequently, the plates were incubated with HRPconjugated goat anti-mouse IgG (1:2000, TransGen Biotech). The unbound secondary antibody was washed off with PBS. Signal reaction was activated utilizing 3,3',5,5'-tetramethylbenzidine (TMB) substrate, and then stopped with $2 \mathrm{M} \mathrm{H}_{2} \mathrm{SO}_{4}$, after which the absorbance was read at $\mathrm{OD}_{450}$. Tested samples that gave an absorbance value greater than 0.080 were defined as positive.

\section{Generation of monoclonal antibodies}

The monoclonal antibodies were produced based on the protocol described in "Antibodies", A laboratory manual edited by Ed Harlow and David Lane [22]. Briefly, BALB/c mice were subcutaneously immunized with $100 \mu \mathrm{g}$ of recombinant PDCoV N protein mixed with Freund's complete adjuvant (Sigma-Aldrich), followed by two boosts with $100 \mu \mathrm{g}$ of recombinant PDCoV N protein mixed with Freund's incomplete adjuvant (Sigma-Aldrich), at 2 weeks intervals.
Serum samples collected on the tenth day after the third immunization were tested. The titer of serum samples was detected using the established ELISA described above; when the titer was higher than 1:10,000, $100 \mu \mathrm{g}$ of recombinant PDCoV N protein were intraperitoneally (i.p.) injected into the mouse for the final boost. The splenocytes from immunized mice were collected and fused with $\mathrm{sp} 2 / 0$ cells to generate hybridomas. The resulting hybridomas secreting PDCoV N-specific mAbs were selected and continuously subcloned at least three times to verify their clonality. To acquire $\mathrm{mAb}$ in ascitic fluid, the hybridomas were transplanted intraperitoneally into mice, and once the abdomens of the mice swelled, the resulting ascitic fluid was collected and stored at $-20{ }^{\circ} \mathrm{C}$.

\section{Western blot}

After being infected with PDCoV or transfected with PDCoV wildtype N-protein-expressing plasmids and/or mutants with lip2000, LLC-PK1 cells were lysed with lysis buffer (containing 3\% DTT, $0.065 \mathrm{~mol} / \mathrm{L}$ Tris- $\mathrm{HCl}$ [PH 6.8], 4\% SDS and 30\% glycerol) supplemented with $1 \mathrm{mM}$ phenylmethylsulfonyl fluoride (PMSF) and then subjected to western blot. Briefly, the cell lysate samples were boiled in $1 \times$ Laemmli buffer, separated by SDSPAGE, and electroblotted onto a polyvinylidene difluoride (PVDF) membrane (Bio-Rad). The membrane was then blocked with PBST (PBS with $0.05 \%$ Tween-20) containing $5 \%$ milk, incubated with mouse anti-HA or anti- $\beta$-actin antibody at 1:2500, and subsequently incubated with HRPconjugated goat anti-mouse IgG at 1:2500 before being developed with the ECL western blot substrate.

\section{Indirect immunofluorescence assay (IFA)}

To examine the subcellular localization of wild type and artificial mutant PDCoV N proteins. LLC-PK1 cells were transfected with $2 \mu \mathrm{g}$ of the indicated plasmids or with negative vectors or infected with PDCoV when cells 
gown on microscope coverslips in 24-well plates reached approximately $80 \%$ confluence. The cells were subsequently harvested for fixation with $4 \%$ paraformaldehyde for $10 \mathrm{~min}$, followed by permeabilization with $0.1 \%$ Triton $\mathrm{X}-100$ for $10 \mathrm{~min}$, and blocking with PBS containing 3\% bovine serum albumin for $1 \mathrm{~h}$. After washed three times with $0.01 \mathrm{M} \mathrm{pH} 7.0 \mathrm{PBS}$, the cells were then incubated separately with mouse $\mathrm{mAb}$ against the $\mathrm{HA}$ tag or PDCoV $\mathrm{N}$ (1:200) for $1 \mathrm{~h}$, followed by FITC-conjugated goat antimouse IgG antibody for $1 \mathrm{~h}$, and finally 4,6-diamidino2-phenylindole (DAPI) for 15 min to detect nuclear DNA. The cells were observed with a confocal laser scanning fluorescent microscope (Olympus Fluoviewer. 3.1, Tokyo, Japan) after washed three times with PBS.

\section{Results}

\section{mAbs produced can react with the PDCoV $\mathrm{N}$ protein}

To generate a monoclonal antibody against the $\mathrm{N}$ protein, the pCold-PDCoV-N vector was constructed, and the resulting recombinant protein, which was expressed and purified from Escherichia coli as described previously [21]. The purified $\mathrm{N}$ protein was used to immunize female $\mathrm{BALB} / \mathrm{c}$ mice. One positive clone, designated as $2 \mathrm{G} 12$, was obtained through ELISA screening. Indirect ELISAs were then performed to determine the mAb titers. They revealed that the antibody titers of ascites and hybridoma cell culture supernatants were over 1,000,000 and 400,000, respectively (Fig. 1a). Western blot analysis showed that mAb $2 \mathrm{G} 12$ specifically reacted with the $E$. coli-produced $\mathrm{N}$ protein, $\mathrm{N}$ protein expressing cells and PDCoV-infected cells (Fig. 1b). IFAs further confirmed the specificity and reactiveness of $\mathrm{mAb} 2 \mathrm{G} 12$ against the $\mathrm{N}$ protein in the context of PDCoV infection (Fig. 1c). These results demonstrate that $\mathrm{mAb} 2 \mathrm{G} 12$ recognizes the PDCoV N protein.

\section{$\mathrm{N}$ protein localizes in the nucleolus of both cells ectopically expressing $\mathrm{N}$ protein and cells infected with PDCoV}

To determine the subcellular distribution of the PDCoV $\mathrm{N}$ protein, the pCAGGS-HA-PDCoV-N vector was constructed and transfected into LLC-PK1 cells. The results of a western blot analysis showed that the PDCoV N protein was expressed normally (Fig. 2a). Next, the results of an IFA analysis of LLC-PK1 cells transfected with pCAGGSHA-PDCoV-N demonstrated that although the fluorescence indicating the presence of the $\mathrm{N}$ protein was predominantly
(A)

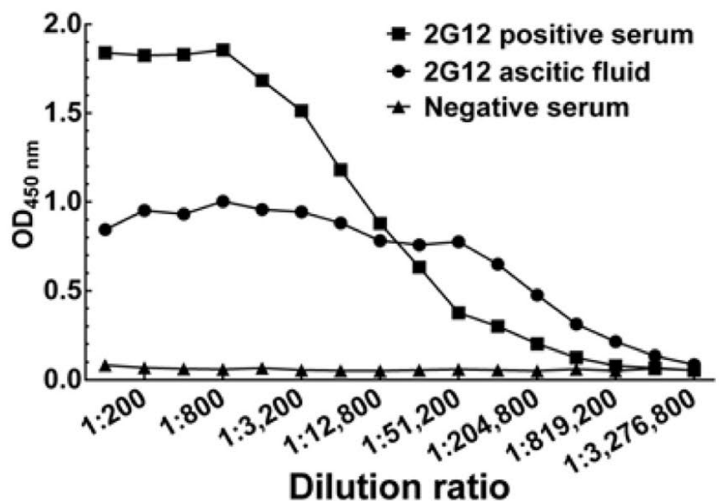

(B)

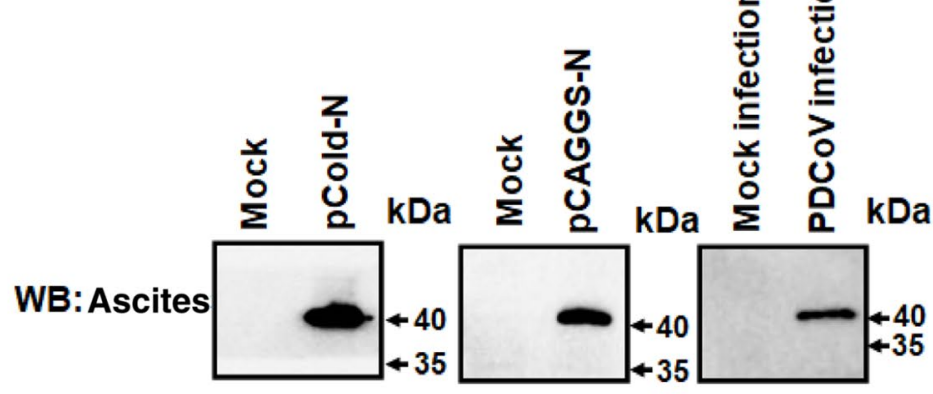

(C)

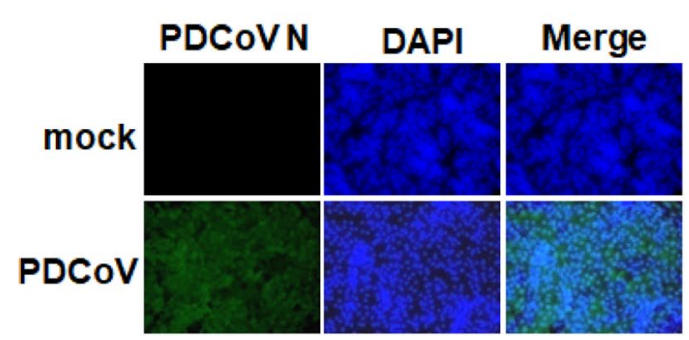

Fig. $1 \mathrm{mAb}$ against PDCoV $\mathrm{N}$ protein generated. a Titers of antiPDCoV $\mathrm{N}$ protein $\mathrm{mAb}$ from Ascites and cell culture supernatants from a monoclonal hybridoma cell line were analyzed by ELISA. Serum from a mock vector immunized mouse acted as a control. The coating concentration of PDCoV $\mathrm{N}$ protein was $5 \mu \mathrm{g} / \mathrm{ml}$. The optical density (OD) values of each point represent the mean value and standard deviation from three determinations $(n=3)$. b Purified recombinant PDCoV-N protein samples or lysates of LLC-PK1 cells that had been transfected with pCAGGS-HA-PDCoV $\mathrm{N}$ or infected with PDCoV were subjected to western blotting with anti-PDCoV $\mathrm{N}$ protein $\mathrm{mAb}$. c LLC-PK1 cells were infected with PDCoV, then fixed with paraformaldehyde for an IFA. The green and blue signals indicate PDCoV N and DAPI, respectively. Fluorescent cells were imaged using confocal laser scanning microscopy 
Fig. 2 PDCoV N protein distributes in both the nucleolus and cytoplasm. a LLC-PK1 cells transfected with pCAGGSHA-PDCoV-N plasmids were subjected to western blotting using anti-HA antibodies or $\beta$-actin antibodies. b LLCPK1 cells were transfected with pCAGGS-HA-PDCoV$\mathrm{N}$ vectors or infected with PDCoV, then fixed with Triton $\mathrm{X}-100$. After incubation with mouse monoclonal antibodies against $\mathrm{HA}$ or PDCoV-N protein and rabbit polyclonal antibody against B23, and then cells were stained with DAPI. The cells were observed and photographed using a confocal laser scanning microscope. The $\mathrm{N}$ protein is colored green, and B23 is colored red
(A)

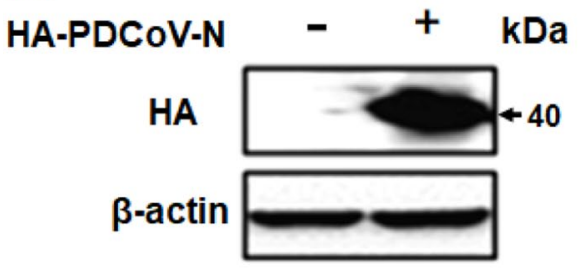

(B)

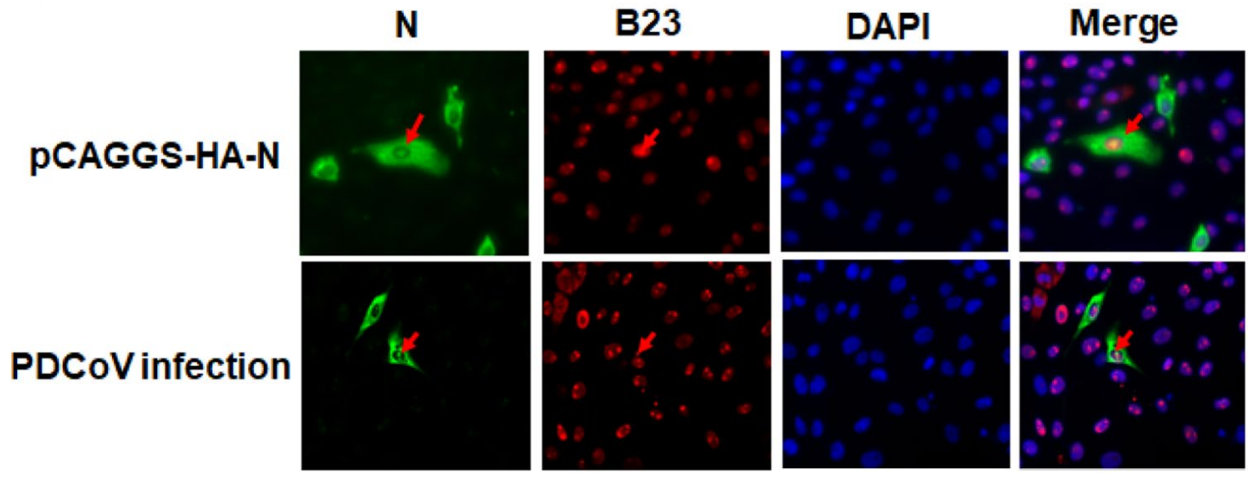

observed in the cytoplasm, some fluorescence was also observed in the nucleolus for a low percentage in ectopic $\mathrm{N}$-expressing cells. The nucleolus location was confirmed by $\mathrm{B} 23$, which is a nucleolar biomarker. A similar result was observed in the context of PDCoV infection (Fig. 2b), indicating that PDCoV N protein localizes in cytoplasm and can also be imported into nucleolus.

\section{At least one of the predicted NoLS is critical for nucleolar localization}

To identify potential localization signals in the PDCoV N protein, putative NoLSs were predicted using the online algorithm NLStradamus, (https://www.moseslab.csb.utoro nto.ca/NLStradamus/2 [23]. An analysis showed that three regions, i.e., the including 157 th arginine residue, amino acid residues 161-197, and amino acid residues 295-318, might play a role in $\mathrm{N}$ protein localization as a NoLS (Fig. 3a). To investigate whether these predicted signals contribute to the subcellular trafficking of the $\mathrm{N}$ protein, the 157th arginine was mutated to an alanine with amino acid residues 161-197 and 295-319 deletions in an N protein mutant named $\mathrm{N}^{\mathrm{R} 157 \mathrm{~A} \Delta 161-197 \Delta 295-318}$ (Fig. 3b). Western blotting confirmed that $\mathrm{N}^{\mathrm{R} 157 \mathrm{~A} \Delta 161-197 \Delta 295-318}$ can be expressed normally in LLC-PK1 cells (Fig. 3c), and an IFA showed that this mutant was only located in the cytoplasm (Fig. 3d), indicating that the 157th arginine residue, and/or amino acid residues 161-197, and/or amino acid residues 295-318 are indispensable for the $\mathrm{N}$ nucleolar localization.

\section{Deletion of the N protein amino acids at 295-318 abrogates the nucleolar distribution of the $\mathbf{N}$ protein}

To map the residues responsible for the $\mathrm{N}$ protein nucleolar localization, $\mathrm{N}$ protein mutants with an alanine as amino acid 157 and/or a deletion of amino acids at the position 161-197 and/or a deletion of amino acids at 295-319 were constructed and transfected into LLC-PK1 cells, which were then subjected to immunoblotting. All mutants were expressed normally (Fig. 4a, b). IFA and confocal microscopy revealed that all the $\mathrm{N}$ protein mutants with deleted amino acids 295-319 $\left(\mathrm{N}^{\Delta 161-197 \Delta 295-319}, \mathrm{~N}^{\mathrm{R} 157 \mathrm{~A} \Delta 295-319}\right.$, and $\mathrm{N}^{\Delta 295-319}$ ) had abrogated nucleolar localization compared with wildtype $\mathrm{N}$ protein. The other $\mathrm{N}$ protein mutants that contained amino acids $295-319\left(\mathrm{~N}^{\mathrm{R} 157 \mathrm{~A} \Delta 161-197}, \mathrm{~N}^{\mathrm{R} 157 \mathrm{~A}}\right.$, and $\mathrm{N}^{\Delta 161-197}$ ) were still able to distribute in both the cytoplasm and nucleolus. This result indicates that amino acids 295-319 are responsible for the nucleolar localization of the $\mathrm{N}$ protein of PDCoV.

\section{Discussion}

Coronavirus $\mathrm{N}$ proteins show low amino acid homology, but they share several conserved functions, including immune regulation. Like the $\mathrm{N}$ proteins from $\alpha$-coronavirus or $\beta$-coronavirus, the PDCoV $\mathrm{N}$ protein also possesses an IFN-inhibition function via interfering dsRNA and PACT binding to RIG-I or RIG-I K63-linked polyubiquitination 
(A)

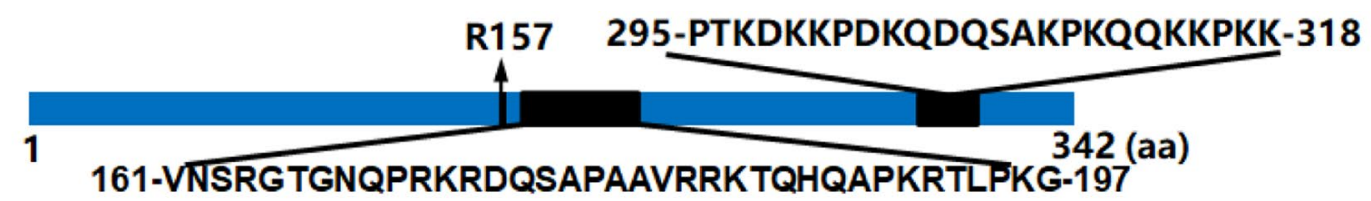

ATGGCTGCACCAGTAGTCCCTACTACTGACGCGTCTTGGTTTCAGGTGCTCAAAGCTCAAAACAAAAAGGCTACTCATCCTC

AGTTTCGTGGCAATGGAGTTCCGCTTAACTCCGCCATCAAACCCGTTGAAAACCATGGCTACTGGCTGCGTTACACCAGAC

AAAAGCCAGGTGGTACTCCGATTCCTCCATCCTATGCCTTTTATTATACTGGCACAGGTCCCAGAGGAAATCTTAAGTATGGT

GAACTCCCTCCTAATGATACCCCAGCAACCACTCGTGTTACTTGGGTTAAGGGTTCGGGAGCTGACACTTCTATTAAGCCTC

ATGTTGCCAAACGCAACCCCAACAATCCTAAACATCAGCTGCTACCTCTCCGATTCCCAACCGGAGATGGCCCAGCTCAAG

GTTTCAGAGTTGACCCCTTCAACGCTAGAGGAAGACCTCAGGAGCGTGGAAGTGGCCCAAGATCTCAATCTGTTAACTCC

AGAGGCACAGGCAATCAGCCCAGGAAACGCGACCAATCTGCACCCGCTGCGGTACGTCGTAAGACCCAACATCAAGCTCC

-VNSRGTGNQPRKRDQSAPAAVRRKTQHQAPKRTLPKG-

CAAGCGGACTTTACCTAAGGGTAAAACCATTTCTCAGGTATTTGGCAACCGGTCTCGTACTGGTGCCAATGTCGGCTCTGC

AGACACTGAGAAGACGGGTATGGCTGATCCTCGCATCATGGCTCTAGCCAGACATGTGCCTGGTGTTCAGGAAATGCTTTT

CGCTGGCCACCTTGAGAGCAACTTTCAGGCGGGGGCAATTACCCTTACCTTCTCTTACTCAATCACAGTCAAGGAGGGTTC

TCCTGACTATGAGAGACTTAAGGATGCGCTCAACACGGTCGTTAACCAGACCTATGAGCCACCCACCAAACCAACTAAGGA

CAAGAAGCCTGACAAACAAGACCAGTCTGCTAAACCCAAACAGCAGAAGAAACCTAAAAAGGTAACTCTGCCAGCAGAC

-PTKDKKPDKQDQSAKPKQQKKPKK-

AAACAGGATTGGGAGTGGGATGATGCTTTTGAGATAAAGCAGGAATCAGCAGCGTAGTAA

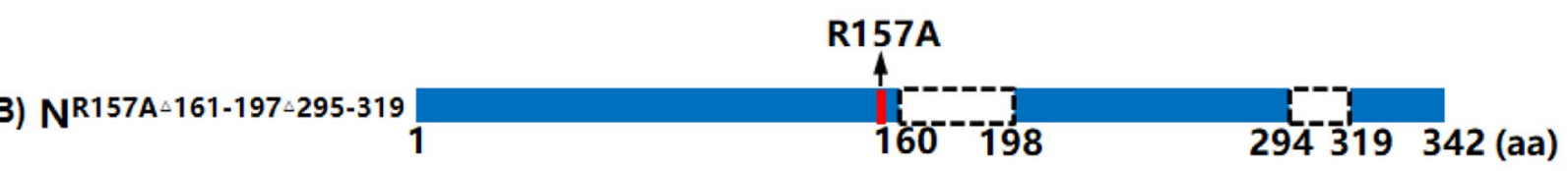

(C)
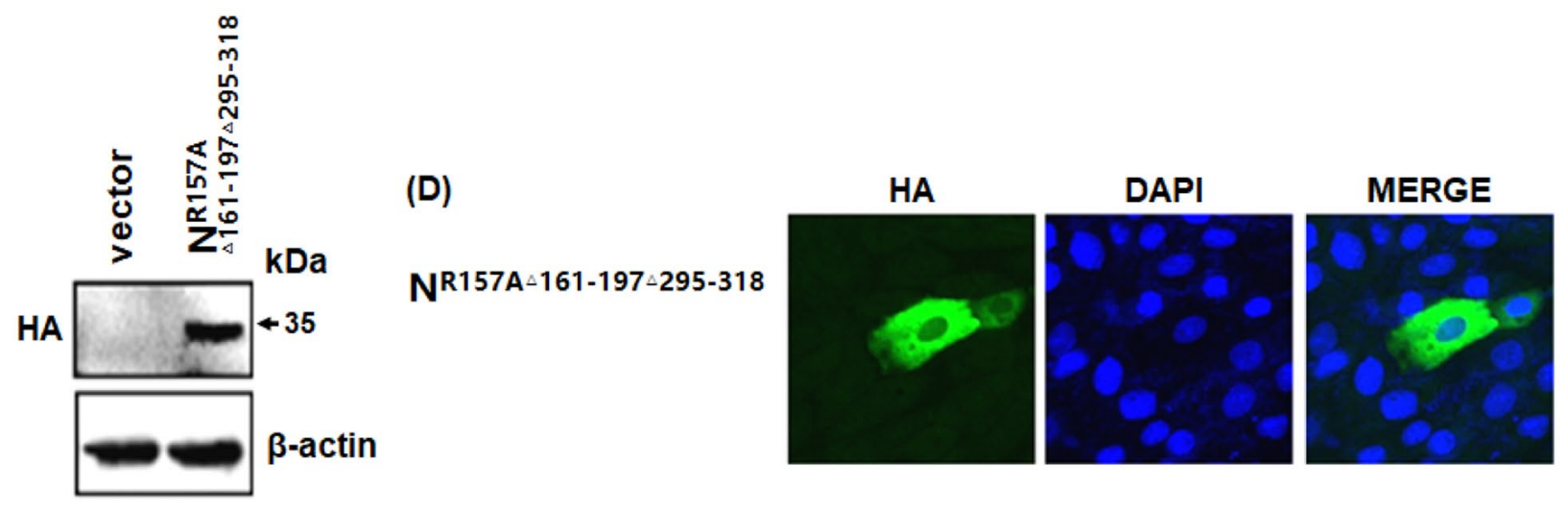

Fig. 3 Putative NoLSs are critical for PDCoV N nucleolar localization. $\mathbf{a}$ and $\mathbf{b} \mathrm{A}$ schematic diagram of $\mathrm{PDCoV} \mathrm{N}$ protein (a) and PDCoV N mutant $\mathrm{N}^{\mathrm{R} 157 \mathrm{~A} \Delta 161-197 \Delta 295-318}$ (b) is shown. Below the diagram is the nucleotide sequence of PDCoV N. Red words in the $5^{\prime}$ and $3^{\prime}$ are start and stop codons. Words underlined are mutated or deleted, and indicated amino acids are shown below. The amino acid sequence is listed above the black boxes or bars. The dashed box represents an internal deletion; the red bar represents a mutant in which the amino acid site 157 Arg was replaced by Ala; and the numbers indicate the amino acid position. c A western blotting analysis of LLC-PK1 cell lysates expressing mutant $\mathrm{N}^{\mathrm{R} 157 \mathrm{~A} \Delta 161-197 \Delta 295-318}$ was performed using anti-HA antibodies. (D) LLC- PK1 cells were transfected with the mutant $\mathrm{N}^{\mathrm{R} 157 \mathrm{~A} \Delta 161-197 \Delta 295-318}$, then fixed with paraformaldehyde for an IFA. The recombinant proteins are colored green and the nucleus is colored blue. Images were examined as described in Fig. 1c 
(A)

$N^{\triangleleft 161-197 \triangleleft 295-318}$

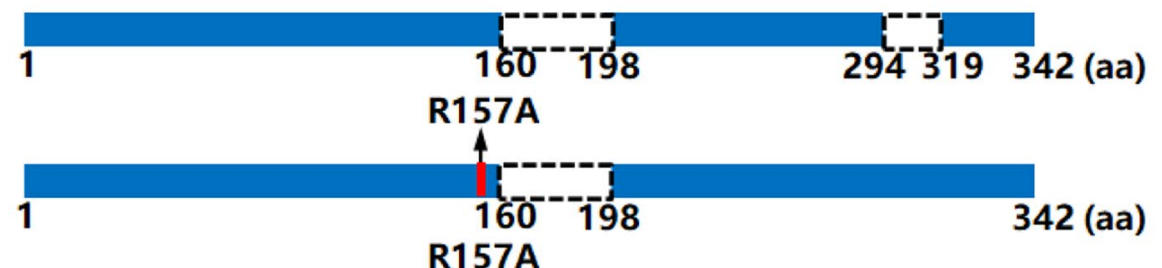

NR157A $\triangle 161-197$

$N^{R 157 A-295-318}$

4

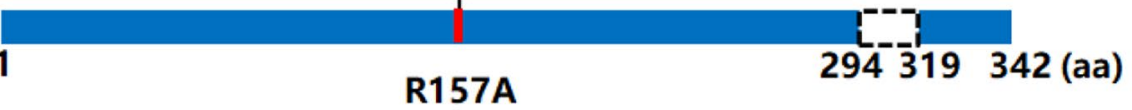

NR157A

4

$N^{\triangle 161-197}$

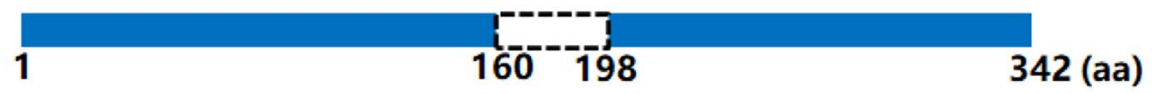

$N^{-295-318}$

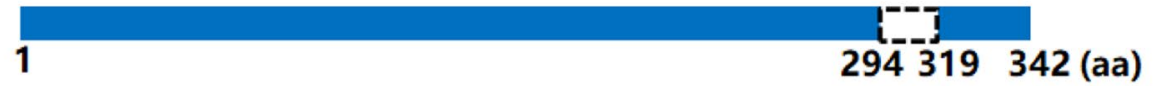

(B)

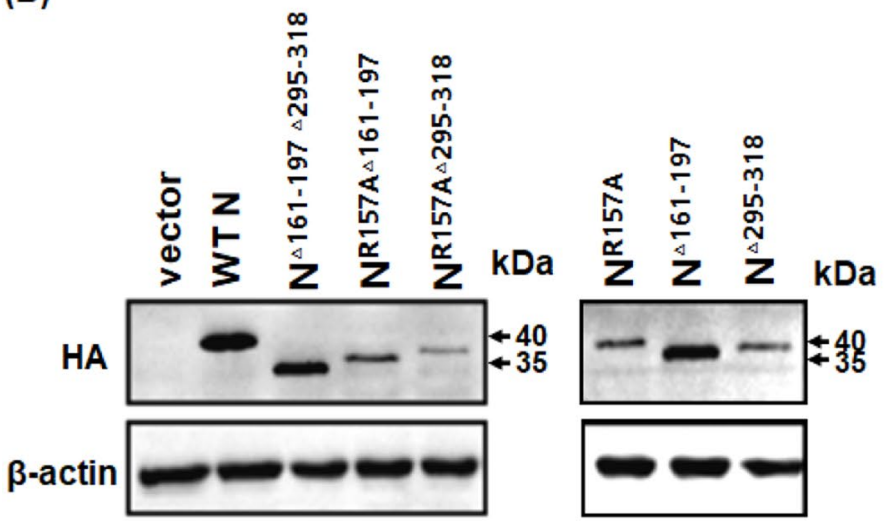

(C)

$N^{-161-197 \triangleleft 295-318}$

HA

DAPI

MERGE

NR157A $\triangle 161-197$
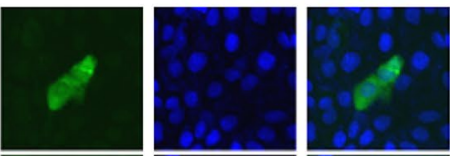

NR157A $\triangle 295-318$
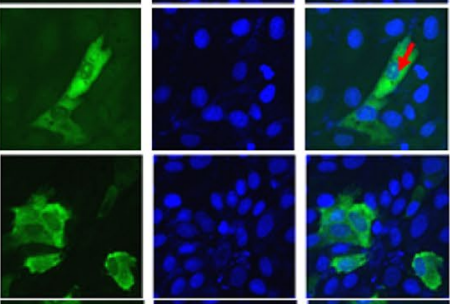

NR157A

$N^{\triangle 161-197}$
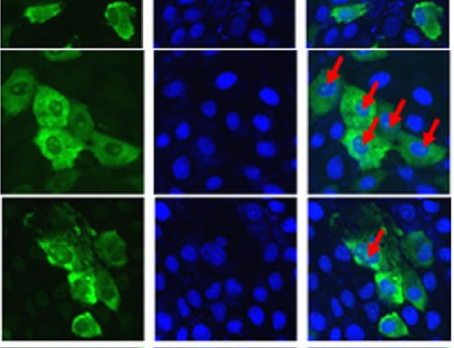

$N^{-295-318}$
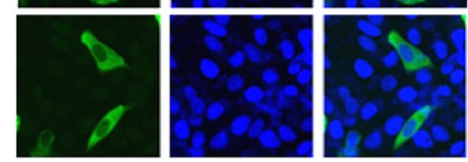

Fig. 4 Amino acid residues 295-318 of the PDCoV N protein are indispensable for $\mathrm{N}$ nucleolar localization. a A schematic diagram of PDCoV $\mathrm{N}$ mutants, represented as described above. b LLCPK1 cells were transfected with expression vectors for the mutants $\mathrm{N}^{\Delta 161-197 \Delta 295-318}, \mathrm{~N}^{\mathrm{R} 157 \mathrm{~A} \Delta 161-197}, \mathrm{~N}^{\mathrm{R} 157 \mathrm{~A} \Delta 295-318}, \mathrm{~N}^{\mathrm{R} 157 \mathrm{~A}}, \mathrm{~N}^{\Delta 161-197}$ and $\mathrm{N}^{\Delta 295-318}$ and then lysed for immunoblotting with anti-HA anti-

[14, 24-26]. Little research into the function of PDCoV N protein has been conducted, but a recent study showed that PDCoV N could upregulate two HSP70 family members, bodies and anti- $\beta$-actin antibodies. $\mathbf{c}$ LLC-PK1 cells were transfected with the mutants $\mathrm{N}^{\Delta 161-197 \Delta 295-318}, \mathrm{~N}^{\mathrm{R} 157 \mathrm{~A} \Delta 161-197}, \mathrm{~N}^{\mathrm{R} 157 \mathrm{~A} \Delta 295-318}$ $\mathrm{N}^{\mathrm{R} 157 \mathrm{~A}}, \mathrm{~N}^{\Delta 161-197}$ and $\mathrm{N}^{\Delta 295-318}$, then subjected to an IFA. Mutant proteins are colored green, and the nucleus is colored blue. Fluorescent images were acquired as described in Fig. 1c

glucose-regulated protein 78 (GRP78) and heat shock cognate $70-\mathrm{kDa}$ protein (HSC70), which may facilitate virus infection. Furthermore, that study also observed that the $\mathrm{PDCoV} \mathrm{N}$ protein can localize in the both nucleolus and the 
cytoplasm in PDCoV N protein expressing-cell lines [27], which is consistent with our findings here, where we generated $\mathrm{mAb}$ against the PDCoV $\mathrm{N}$ protein and confirmed that the $\mathrm{N}$ protein is distributed in either the cytoplasm alone, or in both the nucleolus and cytoplasm. Moreover, in the present study, we identified a functional NoLS that is critical for the nucleolus localization of the $\mathrm{N}$ protein of PDCoV.

The $\mathrm{N}$ proteins of Coronaviridae family members, including PEDV, avian IBV and severe acute respiratory syndrome coronavirus (SARS-CoV), have been reported to localize in the nucleolus $[17,28,29]$. The subcellular localization of the PDCoV N protein differs slightly from those of the $\mathrm{N}$ proteins of other CoVs. The $\mathrm{N}$ protein of PDCoV can localize in the cytoplasm alone or in both the cytoplasm and nucleolus, similarly to the $\mathrm{N}$ proteins of PEDV, a member in the genus Alphacoronavirus and IBV, a member in the genus Gammacoronavirus. The N-terminal domains of PEDV and IBV N proteins are both necessary and sufficient for nucleolar retention $[17,30]$, whereas the PDCoV N protein NoLS is located in the C-terminal domain (CTD). In contrast, the $\mathrm{N}$ protein from SARS-CoV is mostly distributed to the cytoplasm, and even a putative NLS is recognized in its the CTD [20,29].

The nucleolus is a phase-separated cell condensate, which comprised three subcompartments: fibrillar centers (FCs), the dense fibrillar component (DFC), and the granular component (GC) [31]. The nucleolus is plurifunctional; it was primarily identified as a site of ribosome biogenesis [32], but later was found to participate in many biological processes including tRNA and mRNA processing, cell cycle regulation and cellular aging [33]. The replication, transcription, and virion assembly of most RNA viruses occur in the cytoplasm of an infected cell. Although the reason(s) why proteins from cytoplasmic RNA viruses are imported into the nucleolus are still unknown, it has been proven that the association of viral proteins with components in the nucleolus notably contributes to efficient viral replication. The capsid protein of West Nile virus (WNV) is a convincing example of this phenomenon, and it was demonstrated to interact with the nucleolar RNA helicase DDX56 and relocate it from the nucleoli to virus assembly sites for WNV particle assembly [34-36]. Additionally, default in the nucleolar localization of the Japanese Encephalitis Virus (JEV) capsid protein impaired the virus replication and pathogenesis of encephalitis induced by JEV [37]. Our data demonstrate that the N protein of PDCoV is found in the nucleolus. However, the nucleolar components with which PDCoV N combines and the functions in which they are involved need to be investigated in further studies.

Acknowledgements This work was supported by grants from The National Natural Science Foundation of China (Grant No. 31860704), Jiangxi Province Project (Grant Nos. GJJ170261, 20192BAB214023) and Program for Jiangxi Agriculture Research System (Grant No. JXARS-01). We thank Katie Oakley, PhD, from Liwen Bianji, Edanz Editing China (www.liwenbianji.cn/ac), for editing the English text of a draft of this manuscript.

Author contributions ZD, YT, ND, and JZ conceived and designed the experiments; SL, WG, JC, and JC carried out the experiments; ZD, TW, YY, and DS analyzed the data; ZD, SL, LK, and ND prepared the manuscript draft; and LW, YT, JZ, and ZD reviewed and edited the manuscript.

\section{Compliance with ethical standards}

Conflict of interest The authors declare that they have no conflict of interest.

Ethical approval Animal experiments (JXAULL-20190016) were conducted under the guidelines of the ethics committee of Jiangxi Agricultural University, China and The Care and Use Guidelines of Experimental Animals established by the Ministry of Agriculture of China.

\section{References}

1. Jung K, Hu H, Saif LJ (2016) Porcine deltacoronavirus infection: etiology, cell culture for virus isolation and propagation, molecular epidemiology and pathogenesis. Virus Res 226:50-59

2. Zhang J (2016) Porcine deltacoronavirus: overview of infection dynamics, diagnostic methods, prevalence and genetic evolution. Virus Res 226:71-84

3. Jung K, Hu H, Saif LJ (2017) Calves are susceptible to infection with the newly emerged porcine deltacoronavirus, but not with the swine enteric alphacoronavirus, porcine epidemic diarrhea virus. Arch Virol 162:2357-2362

4. Liang Q, Zhang H, Li B, Ding Q, Wang Y, Gao W, Guo D, Wei $\mathrm{Z}, \mathrm{Hu} \mathrm{H}$ (2019) Susceptibility of chickens to porcine deltacoronavirus infection. Viruses 11(6):573

5. Li W, Hulswit RJG, Kenney SP, Widjaja I, Jung K, Alhamo MA, van Dieren B, van Kuppeveld FJM, Saif LJ, Bosch BJ (2018) Broad receptor engagement of an emerging global coronavirus may potentiate its diverse cross-species transmissibility. Proc Natl Acad Sci USA 115:E5135-e5143

6. Song D, Zhou X, Peng Q, Chen Y, Zhang F, Huang T, Zhang T, Li A, Huang D, Wu Q, He H, Tang Y (2015) Newly emerged porcine deltacoronavirus associated with diarrhoea in swine in China: identification, prevalence and full-length genome sequence analysis. Transbound Emerg Dis 62:575-580

7. Wang YW, Yue H, Fang W, Huang YW (2015) Complete genome sequence of porcine deltacoronavirus strain CH/Sichuan/S27/2012 from Mainland China. Genome Announc. https://doi.org/10.1128/ genomeA.00945-15

8. Fang P, Fang L, Liu X, Hong Y, Wang Y, Dong N, Ma P, Bi J, Wang D, Xiao S (2016) Identification and subcellular localization of porcine deltacoronavirus accessory protein NS6. Virology 499:170-177

9. Fang P, Fang L, Hong Y, Liu X, Dong N, Ma P, Bi J, Wang D, Xiao S (2017) Discovery of a novel accessory protein NS7a encoded by porcine deltacoronavirus. J Gen Virol 98:173-178

10. Masters PS, Sturman LS (1990) Background paper. Functions of the coronavirus nucleocapsid protein. Adv Exp Med Biol 276:235-238

11. Masters PS, Parker MM, Ricard CS, Duchala C, Frana MF, Holmes KV, Sturman LS (1990) Structure and function studies of the 
nucleocapsid protein of mouse hepatitis virus. Adv Exp Med Biol 276:239-246

12. Chang CK, Lo SC, Wang YS, Hou MH (2016) Recent insights into the development of therapeutics against coronavirus diseases by targeting N protein. Drug Discov Today 21:562-572

13. Likai J, Shasha L, Wenxian Z, Jingjiao M, Jianhe S, Hengan W, Yaxian Y (2019) Porcine deltacoronavirus nucleocapsid protein suppressed IFN-beta production by interfering porcine RIG-I dsRNA-binding and K63-linked polyubiquitination. Front Immunol 10:1024

14. Chen J, Fang P, Wang M, Peng Q, Ren J, Wang D, Peng G, Fang L, Xiao S, Ding Z (2019) Porcine deltacoronavirus nucleocapsid protein antagonizes IFN-beta production by impairing dsRNA and PACT binding to RIG-I. Virus Genes. https://doi.org/10.1007/ s11262-019-01673-z

15. Tan YW, Fang S, Fan H, Lescar J, Liu DX (2006) Amino acid residues critical for RNA-binding in the N-terminal domain of the nucleocapsid protein are essential determinants for the infectivity of coronavirus in cultured cells. Nucleic Acids Res 34:4816-4825

16. Emmott E, Munday D, Bickerton E, Britton P, Rodgers MA, Whitehouse A, Zhou EM, Hiscox JA (2013) The cellular interactome of the coronavirus infectious bronchitis virus nucleocapsid protein and functional implications for virus biology. J Virol 87:9486-9500

17. Shi D, Lv M, Chen J, Shi H, Zhang S, Zhang X, Feng L (2014) Molecular characterizations of subcellular localization signals in the nucleocapsid protein of porcine epidemic diarrhea virus. Viruses 6:1253-1273

18. Hiscox JA, Wurm T, Wilson L, Britton P, Cavanagh D, Brooks G (2001) The coronavirus infectious bronchitis virus nucleoprotein localizes to the nucleolus. J Virol 75:506-512

19. Wurm T, Chen H, Hodgson T, Britton P, Brooks G, Hiscox JA (2001) Localization to the nucleolus is a common feature of coronavirus nucleoproteins, and the protein may disrupt host cell division. J Virol 75:9345-9356

20. Timani KA, Liao Q, Ye L, Zeng Y, Liu J, Zheng Y, Ye L, Yang X, Lingbao K, Gao J, Zhu Y (2005) Nuclear/nucleolar localization properties of C-terminal nucleocapsid protein of SARS coronavirus. Virus Res 114:23-34

21. Zhang F, Song D, Guo N, Ye Y, Zhou X, Li A, Zhang M, Peng Q, Chen Y, Huang D, Tang Y (2016) Establishment of a recombinant nucleoprotein-based ELISA for detection of antibodies against newly emerged porcine deltacoronavirus. Chin J Prev Vet Med 388:795-799

22. Harlow E, Lane D (1988) Antibodies: a laboratory manual. Cold Spring Harbor Laboratory, New York

23. Nguyen Ba AN, Pogoutse A, Provart N, Moses AM (2009) NLStradamus: a simple Hidden Markov Model for nuclear localization signal prediction. BMC Bioinform 10:202

24. Ding Z, Fang L, Jing H, Zeng S, Wang D, Liu L, Zhang H, Luo R, Chen H, Xiao S (2014) Porcine epidemic diarrhea virus nucleocapsid protein antagonizes beta interferon production by sequestering the interaction between IRF3 and TBK1. J Virol 88:8936-8945

25. Hu Y, Li W, Gao T, Cui Y, Jin Y, Li P, Ma Q, Liu X, Cao C (2017) The severe acute respiratory syndrome coronavirus nucleocapsid inhibits Type I interferon production by interfering with TRIM25mediated RIG-I ubiquitination. J Virol. https://doi.org/10.1128/ JVI.02143-16

26. Ding Z, Fang L, Yuan S, Zhao L, Wang X, Long S, Wang M, Wang D, Foda MF, Xiao S (2017) The nucleocapsid proteins of mouse hepatitis virus and severe acute respiratory syndrome coronavirus share the same IFN-beta antagonizing mechanism: attenuation of PACT-mediated RIG-I/ MDA5 activation. Oncotarget 8:49655-49670

27. Lee S, Lee C (2015) Functional characterization and proteomic analysis of the nucleocapsid protein of porcine deltacoronavirus. Virus Res 208:136-145

28. Reed ML, Dove BK, Jackson RM, Collins R, Brooks G, Hiscox JA (2006) Delineation and modelling of a nucleolar retention signal in the coronavirus nucleocapsid protein. Traffic 7:833-848

29. You J, Dove BK, Enjuanes L, DeDiego ML, Alvarez E, Howell G, Heinen P, Zambon M, Hiscox JA (2005) Subcellular localization of the severe acute respiratory syndrome coronavirus nucleocapsid protein. J Gen Virol 86:3303-3310

30. Ng LF, Liu DX (2000) Further characterization of the coronavirus infectious bronchitis virus $3 \mathrm{C}$-like proteinase and determination of a new cleavage site. Virology 272:27-39

31. Grob A, McStay B (2014) Construction of synthetic nucleoli and what it tells us about propagation of sub-nuclear domains through cell division. Cell Cycle 13:2501-2508

32. Wang L, Ren XM, Xing JJ, Zheng AC (2010) The nucleolus and viral infection. Virol Sin 25:151-157

33. Tsekrekou M, Stratigi K, Chatzinikolaou G (2017) The nucleolus: in genome maintenance and repair. Int J Mol Sci 18:1411

34. Xu Z, Anderson R, Hobman TC (2011) The capsid-binding nucleolar helicase DDX56 is important for infectivity of West Nile virus. J Virol 85:5571-5580

35. Xu Z, Hobman TC (2012) The helicase activity of DDX56 is required for its role in assembly of infectious West Nile virus particles. Virology 433:226-235

36. Reid CR, Hobman TC (2017) The nucleolar helicase DDX56 redistributes to West Nile virus assembly sites. Virology 500:169-177

37. Mori Y, Okabayashi T, Yamashita T, Zhao Z, Wakita T, Yasui K, Hasebe F, Tadano M, Konishi E, Moriishi K, Matsuura Y (2005) Nuclear localization of Japanese encephalitis virus core protein enhances viral replication. J Virol 79:3448-3458

Publisher's Note Springer Nature remains neutral with regard to jurisdictional claims in published maps and institutional affiliations. 